\title{
Expression of Plasminogen Activator Inhibitor Type 1 by Human Prostate Carcinoma Cells Inhibits Primary Tumor Growth, Tumor-associated Angiogenesis, and Metastasis to Lung and Liver in an Athymic Mouse Model
}

Gerald A. Soff, * Judith Sanderowitz, * Stephen Gately, * Elaine Verrusio, ${ }^{*}$ Ivy Weiss, ${ }^{*}$ Steven Brem, ${ }^{\star}$ and Hau C. Kwaan * ${ }^{*}$ Division of Hematology/Oncology, Department of Medicine, and ${ }^{\ddagger}$ Division of Neurosurgery, Department of Surgery, Northwestern University Medical School, Chicago, Illinois 60611

\begin{abstract}
Expression of urokinase-type plasminogen activator (uPA) by malignant cells correlates with an aggressive phenotype, including increased invasiveness, tumor-associated angiogenesis, and metastases. Plasminogen activator inhibitor type 1 (PAI-1) is undetectable in cells of some aggressive malignancies, but present in the stroma of tumor-associated microvasculature. This analysis of an athymic mouse model of prostate carcinoma further defines the role of the uPA/ PAI-1/plasmin system in primary growth and metastasis. A marked increase in PAI-1 expression was induced in clones of the aggressive human prostate carcinoma line, PC3, by stable transfection. Primary PC-3 tumors, in mice, were significantly smaller when derived from PAI-1 expressing versus control cells. PAI-1 expression reduced the density of tumor-associated microvasculature by $22-38 \%$. Microscopic metastases were quantitated using stable expression of the chromogenic label ( $\beta$-galactosidase) in control and PAI-1 expressing cells. PAI-1 expression resulted in a significant inhibition of lung metastases, and liver metastases. Expression of PAI-1 by malignant prostate cells resulted in a less aggressive phenotype, presumably by inhibition of uPA activity, suggesting pharmacologic or molecular inhibition of uPA activity as a potential therapeutic target. (J. Clin. Invest. 1995. 96:2593-2600.) Key words: prostate carcinoma $\cdot$ plasminogen activator inhibitor type $1 \cdot$ urokinase type plasminogen activator $\cdot$ metastases $\cdot \beta$-galactosidase
\end{abstract}

\section{Introduction}

Components of the plasminogen-plasmin system including urokinase-type plasminogen activator (UPA), ${ }^{1}$ tissue-type plasminogen activator (tPA), and their inhibitors, plasminogen activator inhibitors 1 and 2, (PAI-1 and PAI-2), are found in many

Address correspondence to Hau C. Kwaan, Veterans Administration Lakeside Medical Center, 333 East Huron Street, Chicago, IL 60611. Phone: 312-664-4718; FAX: 312-908-5057.

Received for publication 9 September 1994 and accepted in revised form 18 August 1995.

1. Abbreviations used in this paper: PAI, plasminogen activator inhibitor; tPA, tissue-type plasminogen activator; uPA, urokinase-type plasminogen activator.

J. Clin. Invest.

(C) The American Society for Clinical Investigation, Inc.

0021-9738/95/12/2593/08 \$2.00

Volume 96, December 1995, 2593-2600 tumors and tumor cell lines (1-4). uPA mediates extracellular proteolysis, indirectly by generation of plasmin from plasminogen, or by direct proteolysis $(5,6)$. In a number of malignancies, uPA-mediated proteolysis promotes tumor cell invasion and metastasis. In animal models, inhibition of uPA activity by chemical agents such as amiloride $(7,8)$, or by specific antibody (9), resulted in impaired tumor growth and metastasis. uPA (but not tPA) expression is a negative prognostic parameter, predicting invasive phenotype in human prostate $(10)$, colon $(11,12)$, brain $(13)$, breast $(14,15)$, and lung $(16-18)$ tumors.

PAI-1 inhibits the fibrinolytic activity of uPA, and extracellular matrix degradation by certain malignant cell lines (19), but it is unknown if PAI-1 expression may also inhibit the tumor-associated uPA activities in vivo. Earlier observations had paradoxically shown that the expression of PAI-1 in whole tumor extracts predicted an aggressive phenotype in human brain (13), lung (18), and breast cancer $(14,15)$. More recent detailed immunohistochemical analysis showed that the PAI-1 did not localize to the aggressive malignant cells, but was found in vascular endothelial cells and other host stromal cells (20). Those findings were consistent with the concept that PAI-1 protein in aggressive tumors represents a marker for tumorassociated angiogenesis. The current study was designed to test the hypothesis that induced expression of PAI-1 by malignant cells may result in in vivo inhibition of uPA with reduced tumorassociated angiogenesis and metastases.

Previously published studies of prostate carcinoma suggest that the levels of uPA correlate with an aggressive and invasive phenotype $(21,22)$. PC-3 is an aggressive human prostate carcinoma cell line with high expression of uPA and low expression of PAI-1, while another cell line, DU-145, has an indolent phenotype with less UPA expression and higher PAI-1 expression (21-23). This study used an in vivo model of prostate carcinoma, utilizing an athymic mouse model of genetically altered PC-3 tumors, to prospectively modulate PAI-1 expression in primary tumor growth, tumor-associated angiogenesis, and metastases.

\section{Methods}

$P C-3$ cell culture. A human prostate carcinoma cell line, PC-3, was chosen for its aggressive tumor phenotype and for its expression of uPA. PC-3 cells were obtained from Dr. James Kozlowski (Northwestern University), and all cell culture was in RPMI-1640 media supplemented with $10 \%$ fetal bovine serum, penicillin $(100 \mathrm{U} / \mathrm{ml})$, streptomycin $(100$ $\mu \mathrm{g} / \mathrm{ml}$ ), in $5 \% \mathrm{CO}_{2}$ at $37^{\circ} \mathrm{C}$. PC-3 subclones were derived from passaging at single cell density, to create a genetically homogenous population and reduced random phenotypic variability for subsequent analysis. Of numerous subclones, PC3A was selected based on its high expression of UPA and low expression of PAI-1, comparable to the parent population. PC3A cells were used for subsequent transfection experiments.

UPA and PAI-1 antigen levels. UPA and PAI-1 antigen levels were 
determined by ELISA using the commercial Biopool Tintelize kits (Medical Diagnostic Technologies, Inc., Ventura, CA). uPA activity was assayed using a commercial chromogenic assay with the Chromolize kit (Biopool; Medical Diagnostic Technologies, Inc.). With this method, all uPA in test samples were bound to a monoclonal antibody against uPA on microtiter plates. Single-chain uPA was converted to two-chain form by plasmin. We performed tests both with and without this step to determine both the single-chain and the two-chain forms.

\section{Transfection and selection}

PAI-1-expressing PC 3A cells. The lipofection technique was used for stable transfections of PC3A cells based on the manufacturers protocol (24). Cotransfection of PC3A cells was performed with a 10:1 molar ratio of pEUK-Cl-PAI-1, a vector conferring expression of the native human PAI-1 mRNA and protein and the selectable vector Ko-Neo. pEUK-Cl-PAI-1 was derived by insertion of the cDNA for human PAI1 (25) in the pEUK-C1 eukaryotic expression vector (Clontech Laboratories, Inc., Palo Alto, CA), and was provided as a gift from DuPont Chemical Co. (Wilmington, DE). In the Ko-Neo plasmid, the neomycin phosphotransferase cDNA is expressed by the $\mathrm{SV}_{40}$ promoter, allowing selection of PC3A transfected cells in $400 \mu \mathrm{g} / \mathrm{ml}$ of Geneticin (G418; Gibco-BRL Rockville, MD). $10 \mu \mathrm{g}$ of total plasmid was used per transfection in one $100-\mathrm{mm}$ plate. To facilitate isolation of individual transfected clones, within $12 \mathrm{~h}$ of transfection, the cells were replated in 24-well plates at various dilutions where selection was performed. As a negative control, a parallel transfection was performed with KoNeo alone.

Multiple PC3A-derived clones were isolated from the PAI-1 and control transfections. Successful transfection and expression of the PAI1 protein in test clones was confirmed by Northern blot analysis (26) (Fig. 1) and ELISA for PAI-1 (Table 1). The ELISA was performed on lysates and conditioned media from cell aliquots, cultured in serumfree media for $24 \mathrm{~h}$. PAI-1 antigen levels were normalized to cell number.

Production of $\beta$-galactosidase-expressing clones. To allow for the early detection of metastases an additional PC 3 subclone was derived by lipofection-mediated cotransfection with a 10:1 molar ratio of pCMV- $\beta \mathrm{Gal}$ and $\mathrm{pSV}_{2} \alpha 3$.6. pCMV- $\beta \mathrm{Gal}$ induces prokaryotic $\beta$-galactosidase activity (27) allowing transfected cells to be readily identified in vivo, by staining with the chromogenic substrate $\mathrm{X}-\mathrm{Gal}(28) \cdot \mathrm{pSV}_{2} \alpha 3.6$ induces the expression of the alpha-chain of murine $\mathrm{Na}^{+} / \mathrm{K}^{+}$-ATPase, resulting in resistance to ouabain (29), and allowing for selection of stable clones. One clone (PC-3/ $\beta \mathrm{Gal}$, clone $\mathrm{Q}$ ) was selected for subsequent analysis as it stained uniformly positive for $\mathrm{X}-\mathrm{Gal}$, and was morphologically and phenotypically indistinguishable from the parent $\mathrm{PC}$ 3 line. PC-3/ $\beta$ Gal-Q had similar levels of uPA, uPA-receptor, and PAI1 as the parent PC-3 cells (data not shown). Because PC-3/ $\beta \mathrm{Gal}-\mathrm{Q}$ was selected with ouabain $\left(2 \times 10^{-8} \mathrm{M}\right)$, subsequent transfection utilizing G418 selection could be performed. PAI-1/Ko-Neo cotransfection was performed on PC-3/ $\beta$ Gal-Q cells, as described above, also with a Ko-Neo control transfection. The Tintelize PAI-1 ELISA was used to confirm PAI-1 expression in PC3/ $\beta \mathrm{Gal}-\mathrm{Q}-$ derived clones. PC3/ $\beta \mathrm{Gal}-$ Q-derived PAI-1-expressing and control clones were maintained in both $2 \times 10^{-8} \mathrm{M}$ ouabain and $400 \mu \mathrm{g} / \mathrm{ml} \mathrm{G} 418$ to maintain expression of both $\beta$-galactosidase and PAI-1.

\section{In vitro analysis of clones}

In vitro cell proliferation assay. Cell titer $96 \mathrm{AQ}$ assay (Promega Corp., Madison, WI) is based on a tetrazolium compound, (3-(4,5-dimethylthiazol-2-yl)-5(3-carboxymethoxyphenyl)-2-(4-sulfophenyl)-2H-

tetrazolium, inner salt (MTS or Owen's Reagent) and a coupling reagent, phenazine methosulfate (PMS) being bioreduced by viable cells to form a formazan which is soluble in tissue culture medium. The method is nonradioactive, requires no washing or cell harvesting nor solubilization of the dye formed, so it is ideal for not disturbing cell attachments during any part of the growth or assay procedure which might lead to loss of cells to be counted. Briefly, cells in each of the transfected clones are trypsinized, counted by hemocytometer with viability confirmed by trypan exclusion, and plated as $0.2 \mathrm{ml}$ of $10^{4}$ cells $/ \mathrm{ml}$ in serum containing maintenance medium into 96-well tissue culture plates in a format of 12 replicates/clone, and control wells, 6 each containing PBS and medium alone, respectively. A border of wells containing PBS serves to humidify and eliminate contamination during the incubation periods at $37^{\circ} \mathrm{C}$ and $5 \% \mathrm{CO}_{2}$. Day 0 is assayed before attachment is complete to confirm equal plating at the beginning of the 6-d experiment. The following procedure is repeated at the same time each day on day 1, 3, and 6: $40 \mu \mathrm{l}$ dye mixture $(0.1 \mathrm{ml} \mathrm{PMS}+2.0 \mathrm{ml}$ MTS) is added to each well, using a multichannel pipette, and incubated under tissue conditions for $2 \mathrm{~h}$. Before reading, the plate is tapped gently to distribute the dye produced by the living cells and is read at $492 \mathrm{~nm}$ in a Titertek Multiscan Plate Reader (Titertek, Elfa Oy, Finland). After day 6 the average \pm SD for each cell line for each day was calculated and graphed as a comparison to each of the cell lines grown.

In vitro invasion assay. A modified Boyden chamber (30), the Biocoat Matrigel Invasion Chamber system (Collaborative Biomedical Products, Becton-Dickinson, Bedford, MA) was used in a 24-well tissue plate format, containing 12 inserts, each of which has a $3-\mathrm{cm}^{2}$ polyethylene terephthalate membrane, $8 \mu \mathrm{m}$ pore size, precoated with Matrigel basement membrane matrix at a thickness of $125 \mathrm{~cm}^{2}$. The Matrigelcoated membranes are rehydrated using $0.25 \mu \mathrm{l}$ serum-free culture medium (0.1\% BSA in RPMI-1640) added to the upper chamber and incubating at room temperature for $1.5 \mathrm{~h}$. Cells are prerinsed with incomplete PBS and detached from tissue culture vessels using $1 \mathrm{mM}$ EDTA in incomplete PBS, $\mathrm{pH} 7.4$ at $37^{\circ} \mathrm{C}$ for $10 \mathrm{~min}$. They are then counted by hemocytometer and $2 \times 10^{5}$ cells plated in the upper chamber. A 1:50 dilution of Matrigel in serum-free medium $(0.5 \mathrm{ml})$ was added to the lower chamber to act as chemoattractant. Each cell line was assayed in triplicate. To compare our clones for their potential invasiveness via the plasminogen-plasmin system, human plasminogen $\left(1 \mu \mathrm{g} / 10^{4}\right.$ cells per well) was added to the upper chamber. Plates were incubated humidified at $30^{\circ} \mathrm{C}$ and $5 \% \mathrm{CO}_{2}$. After $24 \mathrm{~h}$ the upper chamber medium was removed, the filter swabbed clean to remove all cells which had not invaded the membrane, rinsed with PBS, and fixed with two changes of cold methanol. The cells were stained with eosin-methylene blue. The membrane was then cut off the insert well and mounted with Aquamount with the underside of the membrane facing up. Cells were counted in five high power fields (400 magnification) and reported as average number per high power field.

Gel electrophoresis and zymography. Samples were electrophoresed in the presence of SDS under denaturing but nonreducing conditions in $10 \%$ polyacrylamide gel (SDS-PAGE) using the Laemmli buffer system (31). Tissue extract samples were equalized when loaded on the gel according to protein concentration, conditioned medium, and cell extracts according to cell number. The method of Grannelli-Piperno and Reich (32) was used for zymography. Briefly, after SDS-PAGE, gels were washed twice for $20 \mathrm{~min}$ with $2.5 \%$ Triton X-100 in Tris $0.1 \mathrm{M}$ Tris $/ \mathrm{HCl}, \mathrm{pH} 8.1$, and layered over agar gel containing casein $(2 \% \mathrm{wt} /$ $\mathrm{vol})$ and plasminogen $(20 \mu \mathrm{g} / \mathrm{ml})$. The plasminogen activator diffused into the agar gel, converting plasminogen to plasmin and resulted in caseinolysis. To differentiate uPA from tPA, other than by molecular weight positions $1 \mathrm{mM}$ amiloride (Sigma Chemical Co., St. Louis, MO) was included in the agar gel which specifically prevents the action of uPA but not of tPA. To distinguish human uPA produced by the tumor cells in the xenografts and the mouse uPA monoclonal antibody against human uPA (American Diagnostica Inc., Greenwich, CT) at $10 \mu \mathrm{g} / \mathrm{ml}$ was incorporated in the casein-agar gel. This goat antibody against human uPA did not inhibit the murine uPA which also had a lower molecular weight than human uPA on SDS-PAGE. To differentiate single-chain from two-chain uPA, samples were first pretreated with 10 $\mathrm{mM}$ diisopropyl fluorophosphate (DFP) (Sigma Chemical Co.) for 30 $\mathrm{min}$ at room temperature before SDS-PAGE. DFP inhibits the two-chain but not the single-chain form of uPA so the absence of a fibrinolytic band confirms the sample as containing two-chain uPA. Urinary uPA containing both high molecular weight and low molecular weight forms of two-chain uPA was used as control. After incubation at $37^{\circ} \mathrm{C}$ for $4-$ $25 \mathrm{~h}$, zymograms were photographed under dark ground illumination. 
Identification of inhibitors (PAI-1) was made using reverse zymography by incorporation of UPA into the gel to lyse the background, leaving the inhibited regions unlysed. The standard for uPA (American Diagnostica Inc.) was used. Control uPA-PAI-1 complex was generated by first activating the 3.5- $\mu \mathrm{g}$ PAI-1 (American Diagnostica Inc.) by boiling for $30 \mathrm{~s}$, cooling slightly, adding excess uPA and incubating at room temperature for $30 \mathrm{~min}$ to permit complex formation. Sample buffer without 2-mercaptoethanol was added to give a resultant uPA standard of $20 \mathrm{mIU} /$ lane. Polyclonal antibody to human uPA was incorporated in the gel to differentiate between mouse uPA and human uPA.

Animal model/primary tumor. Aliquots of $10^{6}$ cells of the transfected clones were resuspended in $0.2 \mathrm{ml}$ sterile Hepes-buffered salt solution (HBSS) and injected subcutaneously, into 3-4-wk-old male athymic mice (Harlan Sprague Dawley Inc., Indianapolis, IN). Measurements of the primary tumors at the site of the subcutaneous injection were made using calipers, expressed as the product of the maximal tumor diameter and the perpendicular diameter in $\mathrm{mm}^{2}$, by a blinded observer.

Tumor extraction. Tumor tissue was cut into small pieces of $3 \mathrm{~mm}^{3}$, and rinsed with PBS. Pieces were blotted, weighed, and homogenized using a polytron homogenizer in $20 \mathrm{vol}$ of acetate-detergent extraction buffer $(0.075 \mathrm{M}$ potassium acetate, $0.3 \mathrm{M} \mathrm{NaCl}, 0.1 \mathrm{M}$-arginine, 0.01 M EDTA, $0.25 \%$ Triton-X 100, pH 4.2) for a total of $30 \mathrm{~min}$ on ice (33). For cultured cell extractions, $30 \mathrm{~s}$ of pulsed sonication on ice was used after PBS-washed cells were scraped from dishes in the above extraction buffer. All samples were centrifuged for 15 minutes at 8,000 $g$ at $4^{\circ} \mathrm{C}$ and supernatants stored at $-70^{\circ} \mathrm{C}$ till assayed.

Analysis of primary tumor-associated angiogenesis. For analysis of tumor-associated angiogenesis, the animals were killed at 6 wk after implantation. Each primary tumor was measured and preserved at $-70^{\circ} \mathrm{C}$ until use for histologic and immunohistochemical analysis. Histologic sections were cut from paraffin blocks prepared from formaldehydefixed tissues, and stained with hematoxylin and eosin. In addition, immunoperoxidase staining of $6 \mu \mathrm{m}$ sections by the technique of Sternberger et al. (34) was performed. Polyclonal anticollagen type IV (BioGenex Laboratories, San Ramon, CA) and polyclonal antilaminin (Sigma Chemical Co.) were used. For angiogenesis, the method of Weidner et al. (35) was followed using modifications by Shigematsu (36) and Eriksdotter-Nilsson (37). The respective stained histologic sections were analyzed by the image analysis system (Quantimet 570; Leica Inc., Deerfield, IL) using a magnification of 250. At this magnification, the size of the measured area was $0.09 \mathrm{~mm}^{2}$. Ten $0.09-\mathrm{mm}^{2}$ fields of tumor devoid of necrosis were examined.

The intensity of neovascularization was determined by two methods. The number of vessels stained positive for collagen type IV was counted in 10 fields of $0.09 \mathrm{~mm}^{2}$ and the mean and SD calculated. The area within each of these 10 fields that stained positive with laminin was also measured by the image analysis system.

Analysis of metastases. Gross examination as well as routine hematoxylin and eosin staining failed to reveal detectable metastases through $8 \mathrm{wk}$. To facilitate detection and quantification of micrometastases, a PC3 subclone, (PC-3/ $\beta$ Gal-Q), was derived by cotransfection of $\mathrm{pSV}_{2} \alpha-3.6$ and $\mathrm{pCMV}-\beta \mathrm{Gal}$. PC $3 / \beta \mathrm{Gal}-\mathrm{Q}$ stained uniformly positive in vitro with the chromogenic substrate, X-Gal (29), and exhibited comparable expression of UPA and PAI-1 as the parent PC3 line (data not shown). Utilizing the same transfection and selection procedure as above, PAI-1 expressing subclones and control subclones were derived from PC-3/ $\beta \mathrm{Gal}-\mathrm{Q}$. PAI-1/ $\beta-\mathrm{Gal}$ and $\mathrm{Ko}-\mathrm{Neo} / \beta-\mathrm{Gal}$ subclones were inoculated subcutaneously, $\left(1 \times 10^{6}\right.$ cells per mouse $)$ into $3-4$-wk-old male athymic mice.

A modification of the X-Gal staining method of Gossler et al. (28) was used to detect $\beta$-Gal positive cells in vivo in the primary and potential metastatic sites. After the killing of the animals, the thorax was exposed, and intracardiac perfusion of $\sim 10 \mathrm{ml}$ of an ice-cold solution of $0.2 \%$ gluteraldehyde and $2 \%$ paraformaldehyde in PBS for tissue fixation. $1 \mathrm{ml}$ of the same fixative was also injected intrabronchially after the trachea was ligated. The primary subcutaneous tumor and various organs including the lungs, liver, kidneys, spleen, and brain

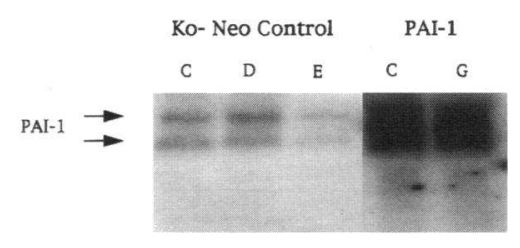

Figure 1. Northern blot of representative PAI-1 and control transfected PC-3 clones. When quantitated by a BAS 2000 Phosphorimager (Fuji Photo Film Co.,

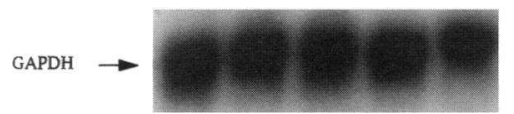
Tokyo, Japan) and normalized to glyceraldehyde 3-phosphate dehydrogenase, the PAI-1

mRNA levels were $>10$-fold increased in successfully PAI-1 transfected clones. Representative Ko-Neo control clones illustrate the baseline PAI-1 mRNA signals.

were removed and placed in the same fixative for $3 \mathrm{~h}$ at $4^{\circ} \mathrm{C}$. They were transferred to a $7 \%$ sucrose in PBS for $2 \mathrm{~h}$ at $4^{\circ} \mathrm{C}$, then to $15 \%$ sucrose in PBS for $3 \mathrm{~h}$ at $4^{\circ} \mathrm{C}$. Between each step, the tissues were washed three times with PBS. A portion of each specimen was also stored at $-70^{\circ} \mathrm{C}$ for further use. The specimens were then embedded in OTC and frozen sections cut at $10 \mu \mathrm{m}$ in a cryostat and placed onto poly-L-lysinecoated slides. Staining was carried out with an X-Gal-staining solution containing, $10 \mathrm{mM}$ potassium ferricyanide, $10 \mathrm{mM}$ potassium ferrocyanide, $1 \mathrm{mM}$ magnesium chloride, $0.03 \% \mathrm{NP}-40$, and $0.1 \% \mathrm{X}-\mathrm{Gal}$ in PBS. Slides were placed in this solution for $3 \mathrm{~h}$ at $37^{\circ} \mathrm{C}$, then rinsed in distilled water, counter-stained with $0.3 \%$ neutral red, air dried, and mounted in Permount.

\section{Results}

\section{Analysis of PAI-1 and UPA expression in transfected} clones

Northern blot analysis confirmed increased PAI-1 mRNA expression in the respective transfected clones (Fig. 1). Based on Northern data, five PAI-1 and three control clones were further characterized by ELISA for the expression of PAI-1 protein. As illustrated in Table I, stably PAI-1-transfected PC3A cells expressed approximately ninefold more PAI-1 protein in the conditioned media compared with control-transfected clones, and approximately fourfold more PAI-1 protein in the cell lysates. The uPA antigen levels were measured in the conditioned media, as well, and no significant differences were observed between the control (mean $814 \mathrm{ng} / 10^{6}$ cells per $24 \mathrm{~h}$ ) and PAI1 transfected clones (mean $1,078 \mathrm{ng} / 10^{6}$ cells per $24 \mathrm{~h}$ ). From these data, the Ko-Neo C, D, and E clones and PAI-1 C, G, and $I$ clones were selected for in vivo characterization in athymic mice. When PC-3/ $\beta \mathrm{Gal}-\mathrm{Q}$ cells were secondarily transfected with pEUK-Cl-PAI-1 and pKo-Neo a similar series of clones were derived with significant PAI-1 protein compared with the control transfected clones (data not shown).

One of the Ko-Neo control transfected clones was found to spontaneously express increased levels of PAI-1 antigen in the conditioned media ( $12.0 \mathrm{ng} / 10^{6}$ cells $/ 24 \mathrm{~h}$ ), comparable to the PAI-1 transfected clones (see Table I) while the uPA antigen ( $1,835 \mathrm{ng} / 10^{6}$ cells $/ 24 \mathrm{~h}$ ) was comparable to the other Ko-Neo and PAI-1 transfected clones. This clone, designated Ko-Neo $B$, was the only Ko-Neo clone to express sufficient PAI-1 to yield a uPA-PAI-1 complex on zymography (Fig. 2) and therefore was independently evaluated to determine if endogenous PAI-1 also could alter the primary growth.

In vitro analysis of PAI-1-expressing PC-3 clones

Effect of PAI-1 expression on $P C-3$ proliferation in vitro. Based on the MTS assay, there was no significant effect on prolifera- 
Table I. PAI-1 Expression by Transfected Clones

\begin{tabular}{cccccc}
\hline $\begin{array}{c}\text { Ko-Neo } \\
\text { (control } \\
\text { clones) }\end{array}$ & $\begin{array}{c}\text { PAI-1 Ag } \\
\text { (conditioned } \\
\text { media) }\end{array}$ & $\begin{array}{c}\text { PAI-1 Ag } \\
\text { (cell } \\
\text { extract) }\end{array}$ & $\begin{array}{c}\text { PAI-1 } \\
\text { (transfected } \\
\text { clones) }\end{array}$ & $\begin{array}{c}\text { PAI-1 Ag } \\
\text { (conditioned } \\
\text { media) }\end{array}$ & $\begin{array}{c}\text { PAI-1 Ag } \\
\text { (cell } \\
\text { extract) }\end{array}$ \\
\hline & $\begin{array}{c}n g / 10^{6} \text { cells } \\
\text { per } 24 h\end{array}$ & $\begin{array}{c}n g / 10^{6} \text { cells } \\
\text { per } 24 h\end{array}$ & & $\begin{array}{c}n g / 10^{6} \text { cells } \\
\text { per } 24 h\end{array}$ & $\begin{array}{c}n g / 10^{6} \text { cells } \\
\text { per } 24 h\end{array}$ \\
C & $<1$ & 2.7 & A & 21 & 18 \\
D & 8 & 9 & B & 35 & not tested \\
E & 4 & $<1$ & C & 39 & 13 \\
& & & G & 55 & 15 \\
& & & I & 24 & 17 \\
Mean & 4.0 & 3.9 & Mean & 34.8 & 15.8 \\
& & & & & \\
\hline
\end{tabular}

PAI-1 antigen levels in cell lysates and cell-free conditioned media were assayed by standard ELISA method. The mean PAI-1 antigen levels were approximately ninefold increased compared with the control clones.

tive rate. The mean doubling time of the control and PAI-1expressing cells were 37 and $40 \mathrm{~h}$, respectively (data not shown), not a significant difference.

Zymography. The zymograms of the respective culture medium and the tumor extracts confirmed the presence of uPA activity that was measured by the chromogenic assays (Fig. 2). In addition, the uPA-PAI-1 complex was demonstrated in the conditioned media from PAI-1-transfected clones, while this complex was not observed in conditioned media from Ko-Neo controls. The tumor extracts from both PAI-1 - transfected and control clones both exhibited the uPA-PAI-1 complex. The uPA-PAI-1 complex was also observed in the conditioned media of the spontaneous PAI- 1 expressing Ko-Neo B clone, although weaker than in the PAI-1-transfected clones.

In vitro analysis of invasion. Using the commercial modified Boyden chamber (Biocoat Matrigel Invasion Chamber System; Collaborative Biomedical Products, Becton-Dickinson) to measure invasion in vitro, the number and fraction of invading, transfected cells was found to be unaffected by PAI- 1 expression, when compared with control cells. The mean (and standard error of mean) of invading cells per high power field was: KoNeo E, 26.3 cells (4.2); Ko-Neo D, 27.7 cells (3.1); PAI-1 G, 25.7 cells (2.7); PAI-1 I, 27.6 cells (4.3).

Study of primary tumors. In the first series of animals, each group consisted of three independent clones, inoculated into four athymic mice per clone. After subcutaneous injection of the cell suspensions, palpable tumors were detected in all the animals at the site of injection, but with variable growth rates (Fig. 3). Tumors derived from the PAI-1 clones were smaller and grew slower than those from the control Ko-Neo clones. The difference in sizes were more noticeable in the first $3 \mathrm{wk}$ and the differences maintained till death at $6 \mathrm{wk}$.

When killed at the end of $6 \mathrm{wk}$, the size of each tumor corresponded to the external palpation measurements. Gross examination failed to reveal metastases in any of the control or PAI-1-expressing mice.

Tumor homogenates were assayed for PAI-1 and uPA antigen, although the data are limited in that some of the tumors, derived from PAI-1 - transfected clones, were too small for analysis. When normalized to milligrams of protein from the tumor extracts, the mean PAI-1 antigen levels were twofold greater in the PAI-1-transfected group versus the control group. (PAI-

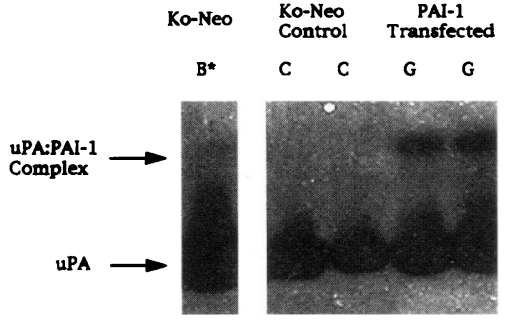

Figure 2. Representative zymography. Zymography illustrates the presence of a uPA-dependent zone of lysis in all control and PAI-1 clones. The PAI-1 transfected clones (illustrated by clone $G$ ) also exhibited a zone of lysis derived from the UPA-PAI-1

complex, indicating PAI-1 expression and activity. * The spontaneously PAI-1 expressing, Ko-Neo B clone, also exhibited a PAI-1-uPA complex, although weaker than the transfected clones. In data not shown, all of the other PAI-1 transfected clones and none of the other Ko-Neo clones exhibited the PAI-1-uPA complex. GAPDH, glyceraldehyde 3phosphate dehydrogenase.

1 -transfected tumors, mean: $59 \mathrm{ng}$ PAI- $1 / \mathrm{mg}$ protein, standard error of mean: 9.6. In control tumors, mean: $32 \mathrm{ng}$ PAI- $1 / \mathrm{mg}$ protein, standard error of mean: 3.6). The uPA antigen levels were comparable between the control and PAI-1-transfected tumors. (In PAI-1 transfected tumors, mean: $113 \mathrm{ng} \mathrm{uPA} / \mathrm{mg}$ protein, standard error of mean: 11.6. In control tumors, mean: $85 \mathrm{ng} \mathrm{uPA} / \mathrm{mg}$ protein, standard error of mean: 21.2 ).

Using the chromogenic functional assay, both the singlechain and two-chained forms of uPA were measured in the tumor extracts. Although, both single-chain UPA and two-chain uPA were detectable in the extracts, no significant differences were observed between the control and PAI-1 expressing tumors (data not shown).

Histologic studies. Histologic observations revealed the presence of poorly differentiated carcinoma in tumors of both $\mathrm{Ko}-\mathrm{Neo}$ and PAI-1 clones. There were morphologic differences in that there were fewer necrotic areas, less mitosis (1-2 per high power field) and less vascularity in the PAI-1 tumors. In the Ko-Neo control tumors, large areas of necrosis, a high mitotic index (3-4 per high power field), and increased vascularity were seen.

To quantitate tumor-associated angiogenesis, computer-assisted image analysis of these parameters were carried out by techniques described in the Methods section. Immunostaining for collagen type IV and for laminin revealed a small decrease in vascular density in the PAI-1 clones (Table II, $P<0.02$ in both cases). The decrease in vascular density may reflect inhibition of tumor-associated angiogenesis by PAI-1.

Analysis of "spontaneously" PAI-1-expressing PC-3 clone. In the course of our initial transfections, one controltransfected clone was derived, designated Ko-Neo B, which was observed to express elevated levels of PAI-1 compared to other control clones. This clone was analyzed separately from the other control clones, which maintained the trace PAI-1 expression of the wild-type. Tumors failed to grow in five of six athymic mice after inoculation of $10^{6} \mathrm{Ko}-\mathrm{Neo} \mathrm{B}$ cells. In the one animal in which Ko-Neo B grew, the primary tumor was of comparable size to the other control clones.

Study of metastasis. To detect and quantitate the effects of PAI- 1 on metastasis, the animal experiments were repeated, using the PC-3/ $\beta$-Gal-Q-derived clones. In preliminary experiments, using PC-3/ $\beta-\mathrm{Gal}-\mathrm{Q}$ cells in athymic mice, metastases were detected in the liver and lung at $6 \mathrm{wk}$. Thus further in vivo analysis in athymic mice involved two PAI-1/ $\beta$-Gal- 


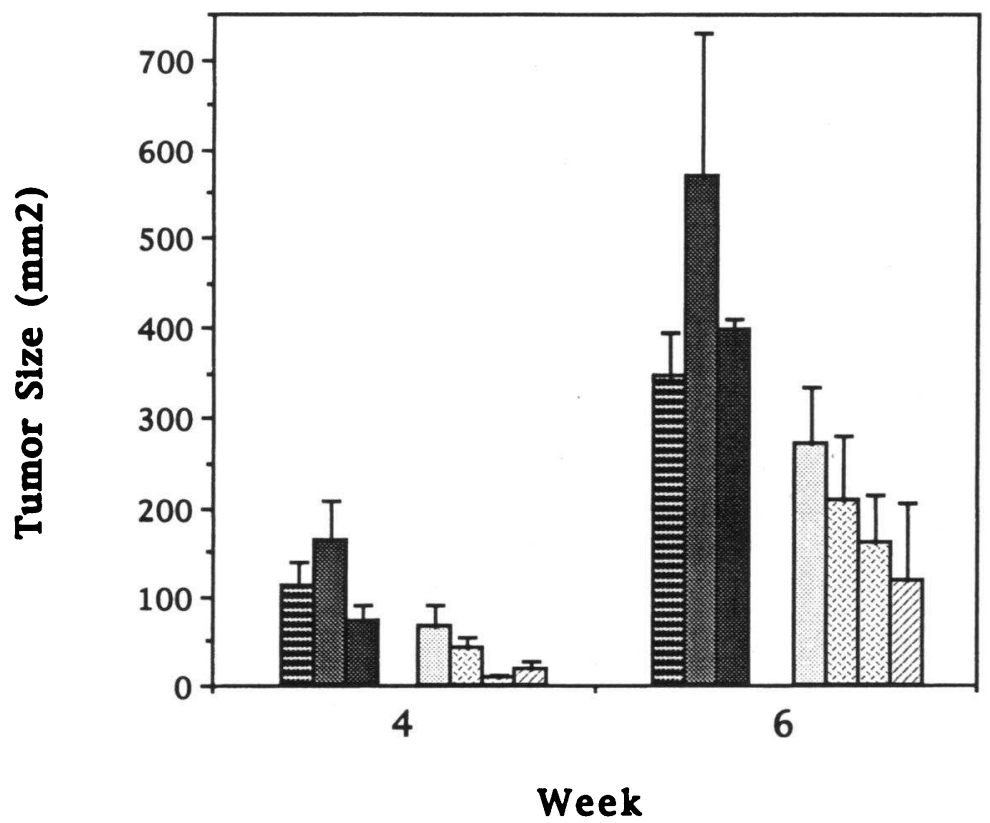

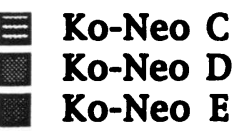

PAI-1
PAI-1
PAI-1
PAI-1
PA

Figure 3. Primary tumor size. A marked inhibition of primary tumor growth was observed by PAI1-transfected clones, when compared with the control Ko-Neo clones. This difference was initially observed throughout the time course of the experiments. transfected clones and two $\mathrm{Ko}-\mathrm{Neo} / \beta-\mathrm{Gal}-$ control clones. To detect differences in the rate of metastatic growth, cohorts of mice inoculated with the PAI- $1 / \beta$-Gal or control $\mathrm{Ko}-\mathrm{Neo} / \beta$ Gal clones were killed at 4-5 and 7-8 wk, with two animals per clone per time point.

The primary subcutaneous tumor and multiple organs were removed and frozen sections stained with X-Gal. No metastases were identifiable at time of dissection, or by routine hematoxylin and eosin histologic staining. In contrast, X-Gal staining revealed important differences in the development of micrometastases between the PAI-1-expressing and control clones.

The most common metastatic site was the lung, followed in frequency by the liver (Figs. 4 and 5, Table III). While occasional metastases were found in the kidney, spleen, and brain, these were too infrequent to allow for meaningful analysis. The number of metastatic lesions in each respective organ was quantitated by a blinded observer. Six frozen sections of each target organ were examined and the number of metastatic lesions were counted in 10 low power fields (magnification of 100). Metastatic sites appeared to consist of 1-10 cells, with the majority of three cells or less. The thickness of the sections $(10 \mu \mathrm{m})$ and the overlapping X-Gal-positive cells made precise determination of the number of metastatic cells per site difficult.

Table II. Quantification of Angiogenesis

\begin{tabular}{lcc}
\hline & $\begin{array}{c}\text { Laminin } \\
\text { (staining as percentage of tumor area) }\end{array}$ & $\begin{array}{c}\text { Collagen IV } \\
\left.\text { (vessels per } 0.09 \mathrm{~mm}^{2}\right)\end{array}$ \\
\hline Ko-Neo & $5.8 \pm 2.2 \%(n=12)$ & $22.3 \pm 2.4 \%(n=5)$ \\
PAI-1 & $3.6 \pm 1.1 \%(n=9)$ & $17.3 \pm 1.6 \%(n=3)$ \\
& $P<0.05$ & $P<0.05$
\end{tabular}

Collagen IV and laminin immunohistochemistry revealed reductions in microvascular density in tumors derived from PAI-1 expressing subclones, compared with control subclones. Data are expressed as mean \pm SEM.
Therefore, the data were quantitated as number of sites per area, independent of the number of cells per site.

The results of lung metastatic counts are shown in Fig. 5. It can be seen that the PAI-1 clones produced significantly less lung metastasis than control clones. There were no differences between the incidence of metastases amongst the three Ko-Neo control clones, and metastases were observed at both time points in all Ko-Neo controls. Only one metastasis was observed in a single PAI-1 mouse at 4-5 wk, and no metastases were observed in all other PAI-1-transfected mice.

A similar analysis was performed to quantitate liver metastases. Because of the smaller number of metastases, results were scored as one or more metastases present per 10 low power fields. A significant reduction in liver metastases was observed by PAI-1 expression at $4-5 \mathrm{wk}$, and when all time points were analyzed (Table III).

\section{Discussion}

The present work is a prospective analysis of the role of PAI1 activity in cancer-associated growth and metastasis. Many prior publications have indicated a correlation between high levels of uPA in human breast $(14,15)$, colon $(11,12)$, lung

Table III. The Development of Liver Metastases Was Inhibited when PC-3-derived Tumors Expressed PAI-1

\begin{tabular}{lcccccc}
\hline \multicolumn{1}{c}{ Time } & \multicolumn{2}{c}{$4-5 \mathrm{wk}$} & \multicolumn{2}{c}{$7-8 \mathrm{wk}$} & \multicolumn{2}{c}{ Total } \\
\hline & Control & PAI-1 & Control & PAI-1 & Control & PAI-1 \\
Metastases & 3 & 0 & 3 & 1 & 6 & 1 \\
No metastases & 3 & 4 & 3 & 3 & 6 & 7 \\
& $P<0.01$ & \multicolumn{2}{c}{ NS } & & $P<0.01$
\end{tabular}

The animals were scored as to the presence or absence of metastases in 10 low power fields. 

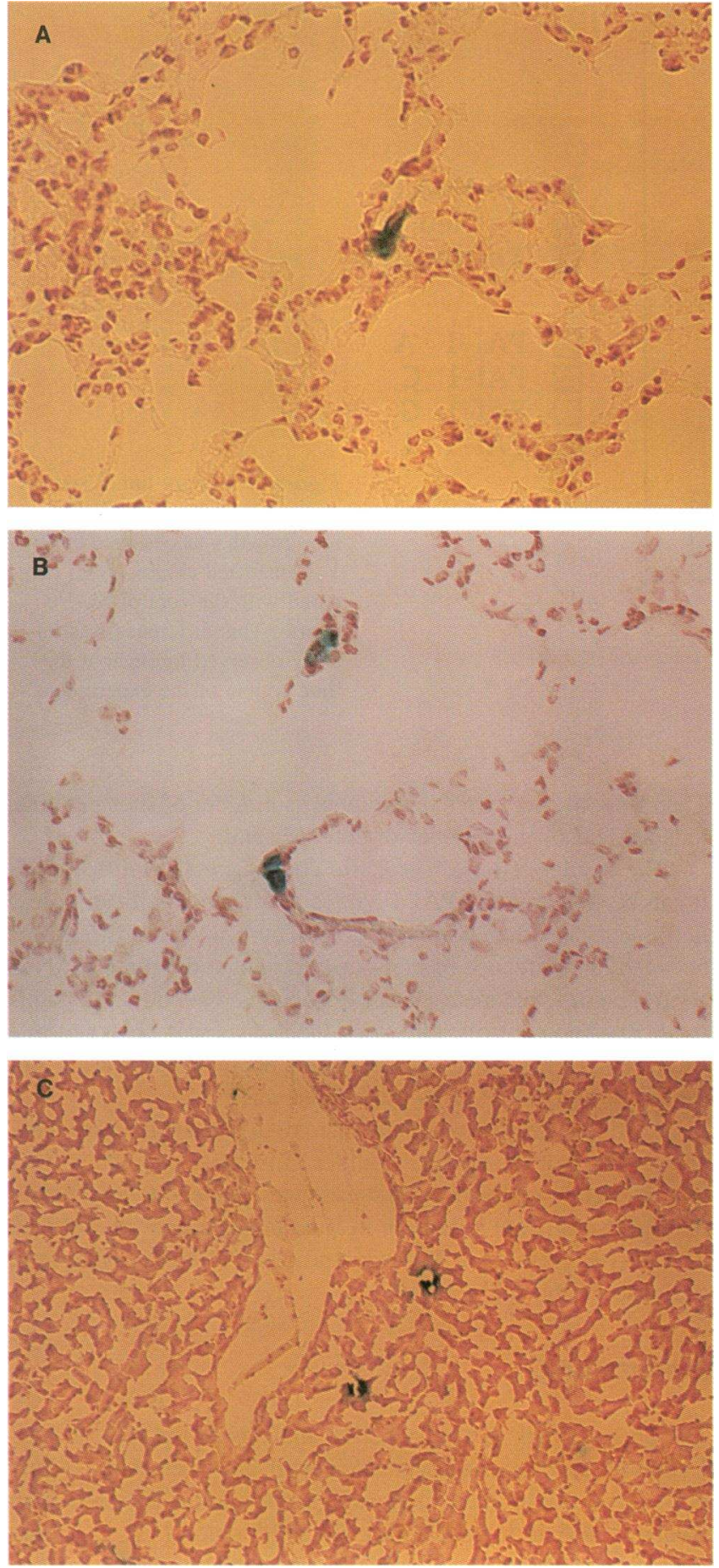

Figure 4. Representative metastases. Representative histologic specimens from lung and liver stained with X-Gal. These represent microscopic metastases derived from PC-3/ $\beta$-Gal-Q cells. Utilization of the $\beta$-galactosidase marker facilitated early detection and quantification of microscopic metastases. The histologic specimens were counterstained with neutral red. ( $A$ and $B$ ) Lung; $(C)$ liver.

(16-18), and prostate (29) cancers and an aggressive phenotype. However, a causal relationship has not been established. In our prospective in vivo study, we created subclones of the aggressive human prostate cancer line PC-3, which differed from control clones only in the expression of PAI-1, a physio-

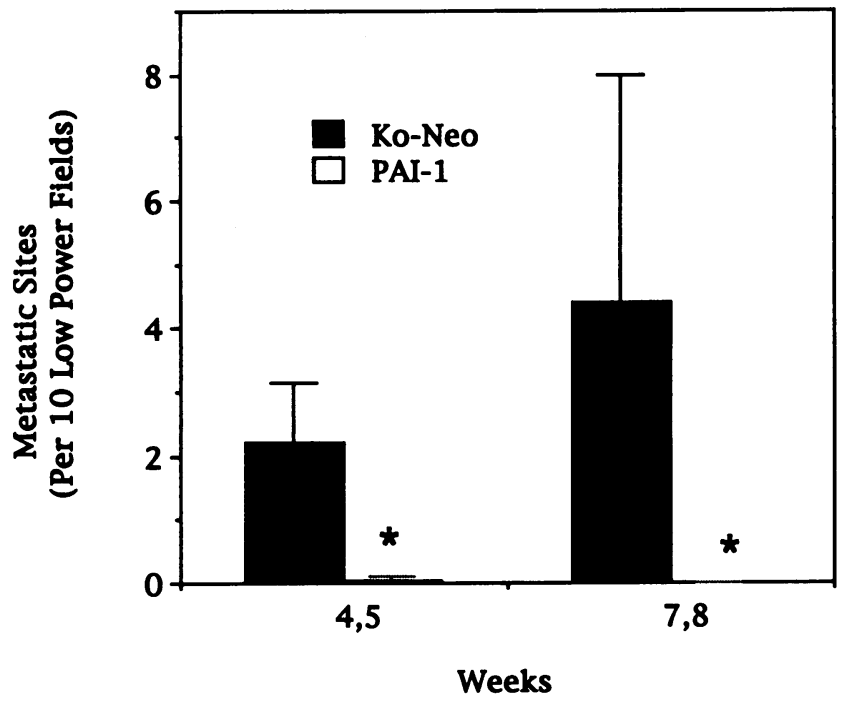

Figure 5. Quantification of metastases. Development of lung metastases by PAI-1 expressing PC-3/ $\beta$-Gal-Q tumors was markedly reduced in comparison to control PC-3/ $\beta$-Gal-Q tumors. The data represent the mean \pm SEM of the frequency of metastatic sites. At least four animals were analyzed at each time point from three independent subclones. $(P$ $<0.01$ at $4-5 \mathrm{wk}$, and $P<0.05$ at $7-8 \mathrm{wk})$. ${ }^{*}$ The bars from the PAI-1 data reflect the observation that the mean metastatic count was only 0.05 per 10 low power fields at $4-5 \mathrm{wk}$, and none detected at 7 8 wk.

logic inhibitor of uPA activity. In our animal model of tumor growth, the specific inhibition of uPA activity by increased expression of PAI-1 resulted in several phenotypic changes. $(a)$ There was a reduction in the size and rate of growth of the primary tumor; $(b)$ tumor-associated angiogenesis was inhibited as evidenced by the reduced microvascular density in the tumor; $(c)$ the number of microscopic metastatic lesions in the lung and liver was reduced.

There are several potential mechanisms by which PAI-1 alters the aggressive phenotype. The catalytic activity of uPA initiates the sequential enzymatic activation of plasminogen and latent metalloproteinases resulting in pericellular matrix degradation and enhancing cell migration and tumor cell invasion. uPA is present in many tumors, either produced by the tumor cells or by adjacent stromal cells. It is less susceptible to inhibition by PAI-1 when bound to its receptor on the cell surface (38). PAI-1 will form a complex with uPA located either in the pericellular environment or bound to the receptor (39). The uPA-PAI-1 complex is then internalized and degraded. Thus a balance is maintained between UPA and PAI-1 activities under physiologic conditions. In the case of tumor cells where increased uPA is present, the excessive uPA activity contributes to the tumor aggressiveness through increased pericellular proteolysis. In our experimental model, an increased production of PAI-1 by the tumor cells would tilt the balance towards a greater inhibition local tumor growth. Likewise, the impaired pericellular proteolysis, mediated by PAI-1, led to reduced tumor invasiveness and metastasis.

In our model of human prostate cancer cells in an athymic mouse, the UPA-receptor and PAI-1 are of human source, while the UPA is a mixture of human (PC-3 produced) and mouse (host produced). As the mouse uPA may have reduced affinity 
for the human UPA receptor, this may reduce the PC-3-bound uPA, and augment the PAI-1 effect.

Analysis of the in vivo behavior, within the group of PAI1-transfected clones, failed to reveal a consistent correlation between tumor size and PAI-1 levels. Of note, the PAI-1 A clone had the lowest level of PAI-1 antigen in the conditioned media, and yielded the fastest growing primary tumor. However, PAI-1 I clone had only slightly more PAI-1 antigen and yielded the slowest growing tumors. This suggests the PAI-1 antigen levels may incompletely reflect the effects of the PAI-1 transfection.

We further took advantage of a spontaneously PAI-1-expressing PC-3 clone, Ko-Neo-B, to independently substantiate the effect of PAI-1 expression on primary tumor growth. Because of the unknown nature of the mutation or other mechanism, by which clone Ko-Neo-B was induced to express PAI1, it was analyzed separately from the PAI-1-transfected clones and the control clones. The resultant suppression of primary tumor growth was more profound than the PAI-1 transfectants, disproportionate to the levels of PAI-1 antigen measured. This may reflect differences in the posttranslational activation of PAI-1 protein between Ko-Neo-B and the PAI-1-transfected clones, or may reflect that a series of alterations in phenotype were present in Ko-Neo-B, which had an additive effect on the tumor growth and invasion.

Several attempts were made to define, in vitro, the phenotypic effects of PAI-1 transfection, which may have contributed to the difference in primary and metastatic growth. The MTS assay for cell proliferation indicated there was no difference in the proliferative rate, when cells were grown in isolated culture. Furthermore, the Boyden chamber assay for tumor cell invasiveness did not reveal reduced invasion through the Matrigel filter by the PAI-1 expressing clones. This discrepancy from the in vivo observations, may reflect that the uPA role in invasion and metastases involves one or more other constituents, not present in this in vitro invasion assay. In previous studies, we found that exogenous PAI-1 does indeed inhibit Matrigel invasion by $\mathrm{PC}-3$ cells, but the concentrations required exceeded the concentration obtained in the conditioned media of our transfected cells (40). Utilizing zymographic analysis, the PAI1 -transfected clones exhibited an additional uPA band, consistent with development of a uPA-PAI-1 complex in the conditioned media, thus confirming the bioactivity of the PAI-1 product.

Angiogenic activity also reflects the balance between uPA and PAI-1 expressions (41). uPA stimulates components of angiogenesis in normal and malignant tissue models. This stimulation includes chemotaxis, proteolytic matrix degradation, and the release of basic fibroblast growth factor from its storage in the basement membrane that in turn can accelerate angiogenesis (42-45). Thus an increase in cellular expression of PAI-1 would be expected to inhibit angiogenesis. The decrease in microvascular density in the high PAI-1-expressing tumors, although by only $22-38 \%$, is consistent with this concept.

In our experiments, a ninefold increase in PAI-1 expression by the malignant PC-3 cells in vitro, resulted in a twofold increase in tumor-associated PAI-1 in vivo. This led to a favorable phenotype, and thus helps to address the apparent paradox that a high PAI-1 content in the homogenates of human tumor samples of brain, lung, and breast malignancies has been observed to be a poor prognostic indicator $(13-15,18)$. That observation is not necessarily in conflict with our results. Immunohisto- chemical and in situ hybridization analysis of tumors has revealed that the endothelial and stromal cells within a tumor express high PAI-1 levels $(20,46)$. The increased PAI-1 in tumor homogenates could thus be reflecting the increased microvascular density (20). Furthermore, decreased PAI-1 expression by breast cancer cells, as assayed by immunohistochemistry, correlates with an aggressive phenotype (20). Based on our current study, the inverse correlation between tumor cell expression of PAI-1 and aggressive phenotype may be causally related.

The inhibition of uPA activity is therefore a potential target for pharmacologic or gene transfer approaches in the management of prostate cancer. Aprotinin, epsilon aminocaproic acid, and tranexamic acid are agents currently available as inhibitors of the uPA/plasmin system and would be candidates for possible in vivo study. Additionally, gene transfer experiments may be used to evaluate possible benefits of hyperexpression of PAI1 in tumors.

\section{Acknowledgments}

The authors are grateful to Dr. Shingo Takano (for vascular density counting).

This work was supported by a Veterans Administration Merit Review Research Grant and a grant-in-aid from the American Cancer Society, Illinois division.

\section{References}

1. Dano, K., P. A. Andreasen, J. Grondahl-Hansen, P. Kristensen, L.S. Nielson, and L. Skriver. 1986. Plasminogen activator, tissue degradation and cancer. Adv. Cancer Res. 44:139-266.

2. Kwaan, H. C. 1992. The plasminogen-plasmin system in malignancy. Cancer Metastasis Rev. 11:291-311.

3. Markus, G. 1988. The relevance of plasminogen activators to neoplastic growth. Enzyme (Basal). 40:158-172.

4. Vassalli, J. D., A.P. Sappino, and D. Belin. 1991. The plasminogen-plasmin system. J. Clin. Invest. 88:1067-1072.

5. Testa, J. E., and J. P. Quigley. 1990. The role of urokinase-type plasminogen activator in aggressive tumor cell behavior. Cancer Metastasis Rev. 9:353-367.

6. Saksela, O. 1985. Plasminogen activation of regulation of pericellular proteolysis. Biochim. Biophys. Acta. 823:35-65.

7. Vassalli, J. D., and D. Belin. 1987. Amiloride selectively inhibits the urokinase-type plasminogen activator. FEBS Lett. 214:187-191.

8. Kellen, J. A., A. Mirakian, and A. Kolin. 1988. Antimetastatic effect of amiloride in an animal tumor model. Anticancer Res. 8:1373-1376.

9. Ossowski, L., G. Clunie, M. T. Masucci, and F. Blasi. 1991. In vivo paracrine interaction between urokinase and its receptor: effect on tumor cell invasion. J. Cell Biol. 115:1107-1112.

10. Heinert, G., J. C. Kirchheimer, H. Pfluger, and H. Binder. 1988. Urokinase type plasminogen activator as a marker for the formation of distant metastasis in prostatic carcinomas. J. Urol. 140:1466-1469.

11. deBruin, P. A., G. Griffoen, H. W. Verspaget, J. H. Verheijen, and C. B. H. W. Lamers. 1987. Plasminogen activators and tumor development in the human colon: Activity levels in normal mucosa, adenomatous tissues, polyps and adenocarcinomas. Cancer Res. 47:4654-4657.

12. Ganesh, S., C. F. M. Sier, G. Griffioen, H. J. M. Vloedgraven, A. deBoer, K. Welvaart, C. J. H. van de Velde, J. H. J. M. van Krieken, J. H. Verheijen, C. B. H. W. Lamers, and H. W. Verspaget. 1994. Diagnostic relevance of plasminogen activators and their inhibitors in colorectal cancer. Cancer Res. 54:40654071.

13. Landau, B. J., H. C. Kwaan, E. N. Verrusio, and S. S. Brem. 1994. Elevated levels of urokinase-type plasminogen activator and plasminogen activator inhibitor type-1 in malignant human brain tumors. Cancer Res. 54:1105-1108.

14. Janicke, R., M. Schmitt, R. Hafter, A. Hollreieder, R. Babic, K. Ulm, W. Grossner, and H. Graeff. 1990. Urokinase-type plasminogen activator (uPA) antigen is a predictor of early relapse in breast cancer. Fibrinolysis. 4:69-78.

15. Duffy, M.J., D. Reilly, C. O'Sullivan, N. O'Higgins, J. J. Fennelly, and P. Andreasen. 1990. Urokinase plasminogen activator, a new and independent prognostic marker in breast cancer. Cancer Res. 50:6827-6829.

16. Markus, G., H. Takita, S. M. Camiolo, H. G. Corasanti, J. L Evers, C. 
and H. Hobika. 1980. Content and characterization of plasminogen activators in human lung tumors and normal lung tissues. Cancer Res. 40:841-848.

17. Oka, T., T. Ishida, T. Nishino, and K. Saugimachi. 1991. Immunohistochemical evidence of urokinase-type plasminogen activator in primary and metastatic tumors of pulmonary adenocarcinoma. Cancer Res. 51:3522-3525.

18. Pedersen, H. J., J. Grondahl-Hansen, D. Francis, K. Osterlind, H. H. Hansen, K. Dano, and N. Brunner. 1994. Urokinase and plasminogen activator inhibitor type 1 in pulmonary adenocarcinoma. Cancer Res. 540:120-123.

19. Cajot, J. C., J. Bamat, G. E. Bergonzelli, E. K. Kruithof, R. L. Medcalf, J. Testuz, and B. Sordat. 1990. Plasminogen activator inhibitor type 1 is a potential natural inhibitor of extracellular matrix degradation by fibrosarcoma and colon carcinoma cells. Proc. Natl. Acad. Sci. USA. 87:6943-6969.

20. Damjanovich, L., C. Turzo, and R. Adany. 1994. Factors involved in the plasminogen activation system in human breast tumors. Thromb. Haemostasis. 71:684-691.

21. Gaylis, F.D., H. N. Keer, M. J. Wilson, H. C. Kwaan, A. A. Sinha, and J. M. Kozlowski. 1988. Plasminogen activators in human prostate cancer cell lines and tumors. Correlation with aggressive phenotype. J. Urol. 142:193-198.

22. Keer, H. N., F. D. Gaylis, J. M. Kozlowski, H. C. Kwaan, K. D. Bauer, A. Akouchi, A. A. Sinha, and M. J. Wilson. 1991. Heterogeneity in cellular levels of expression of plasminogen activators in human prostate cancer cell lines. Invasive cells contain and secrete more uPA. Prostate. 18:201-204.

23. Hollas, W., N. Hoosein, L. W. K. Chung, A. Mazar, J. Henkin, K. Kariko, E. S. Barnathan, and D. Boyd. 1992. Expression of urokinase and its receptor in invasive and non-invasive prostate cancer cell lines. Thromb. Haemostasis. 68:662-666.

24. Felgner P. L, Gadek T. R, M. Holm, R. Roman, H. W. Chan, M. Wenz, J. P. Northrop, G. M. Ringold, M. Danielsen. 1987. Lipofection: a highly efficient, lipid-mediated DNA-transfection procedure. Proc. Natl. Acad. Sci. USA. 84:74137417.

25. Pannekoek, H., H. Veerman, H. Lambers, P. C. L. Verweil, A. J. van Zonneveld, and J. A. Mourik 1986. Endothelial plasminogen activator inhibitor (PAI): a new member of the Serpin gene family. EMBO (Eur. Mol. Biol. Org.) J. 5:2539-2544.

26. Sambrook, J., E. F. Fritsch, and T. Maniatis. 1989. Molecular Cloning: A Laboratory Manual. 2nd Ed. Cold Spring Harbor Laboratory Press, Cold Spring Harbor, NY.

27. MacGregor, G. R, and C. T. Caskey. 1989. Construction of plasmids that express $E$ coli $\beta$-galactosidase in mammalian cells. Nucleic Acids Res. 17:2365.

28. Gossler, A., A. L. Joyner, J. Rossant, and W. C. Skarnes. 1989. Mouse embryonic stem cells and reporter constructs to detect developmentally regulated genes. Science (Wash. DC). 244:463-465.

29. Kent, R. B., J. R. Emanuel, Y. B. Neriah, R. Levenson, and D. E. Housman. 1987. Ouabain resistance conferred by expression of the cDNA for a murine $\mathrm{Na}^{+}$, $\mathrm{K}^{+}$-ATPase subunit. Science (Wash. DC). 237:901-903.

30. Albini, A., Y. Iwanda, H. K. Kleinman, F. R. Martin, S. A. Aaronson, J. M. Kozlowski, and R. N. McEwan. 1987. A rapid in vitro assay for quantitating the invasive potential of tumor cells. Cancer Res. 47:32-39.
31. Laemmli, U. K. 1970. Cleavage of structural proteins during the assembly of the head of bacteriophage T4. Nature (Lond.). 227:680-685.

32. Grannelli-Piperno, A., and E. Reich. 1978. A study of protease-inhibitor complexes in biological fluids. J. Exp. Med. 148:223-234.

33. Camiolo, S. M., M. R. Siuta, and J. M. Madeja. 1982. Improved medium for extraction of plasminogen activator from tissues. Prep. Biochem. 12:297-305.

34. Sternberger, L. A., P. H. Hardy, and J. J. Cuculis. 1970. The unlabelled antibody-enzyme method of immunohistochemistry preparation and properties of soluble antigen-antibody-complex (horse radish peroxidase-antihorse radish peroxidase) and its use in identification of spirocytes. J. Histochem. Cytochem. 18:315-333.

35. Weidner, N., J. P. Semple, W. Welch, and J. Folkman. 1991. Tumor angiogenesis and metastasis-correlation in invasive breast carcinoma. $N$. Engl. $J$. Med. 1-8.

36. Shigematsu, K., H. Kamo, I. Akiguchi, J. Kimura, M. Kameyama, and H. Kimura. 1989. Neovascularization in kainic acid-induced lesions of rat striatum. An immunohistochemical study with laminin. Brain Res. 50:214-222.

37. Eriksdotter-Nilsson, M., H. Bjorklund H., and L. Olson: 1986. Immunohistochemistry: a simple method to visualize and quantitate vascular structures in the mammalian brain. J. Neurosci. Methods. 17:275-286.

38. Ellis, V., T. C. Wun, H. Behrendt, and K. Dano. 1990. Inhibition of receptor-bound urokinase by plasminogen activator inhibitor. J. Biol. Chem. 265:9904-9908.

39. Cubellis, M. V., T. C. Wun, and F. Blasi. 1990. Receptor-mediated internalization and degradation of urokinase is caused by its specific inhibitor. $E M B O$ (Eur. Mol. Biol. Org.) J. 1079-1085.

40. Kwaan, H. C., H. Keer, J. A. Redosevich, J. F. Cajot, and R. Ernst. 1991 Components of the plasminogen-plasmin system in human tumor cell lines. Semin. Thromb. Hemostasis. 17:175-182.

41. Pepper, M.S., D, Belin, R, Montesanio, L. Orci, and J. D. Vassalli. 1990 Transforming growth factor-beta 1 modulates basic fibroblast growth factor-induced proteolytic and angiogenic properties of endothelial cells in vitro. J. Cell Biol. 111:743-755.

42. Yasunaga, C., Y. Nakashima, and K. Sueishi. 1989. A role of fibrinolytic activity in angiogenesis. Quantitative assay using in vitro method. Lab. Invest. 61:689-704.

43. Mignati, P., R. Tsuboi, E. Robbins, and D. B. Rifkin. 1989. In vitro angiogenesis on the human amniotic membrane: requirement for basic fibroblast growth factor-induced proteinase. J. Cell Biol. 108:671-682.

44. Saksela, O., and D. B. Rifkin. 1990. Release of basic fibroblast growth factor-heparan sulfate complexes from endothelial cells by plasminogen activatormediated proteolytic activity. J. Cell Biol. 110:767-775.

45. Flaumenhaft, R., D. Moscatelli, O. Saksela, and D. B. Rifkin. 1989. Role of extracellular matrix in the action of basic fibroblast growth factor: matrix as a source of growth factor for long-term stimulation of plasminogen activator production and DNA synthesis. J. Cell Physiol. 140:75-81.

46. Pyke, C., P. Kristensen, E. Ralf kiaer, J. Grondahl-Hansen, J. Eriksen, F. Blasi, and K. Dano. 1991. Urokinase-type plasminogen activator is expressed in stromal cells and its receptor in cancer cells at invasive foci in human colon adenocarcinomas. Am. J. Pathol. 138:1059-1067. 